\title{
TRADUZINDO A IDENTIDADE DA FAVELA BRASILEIRA NA FRANÇA: JE SUIS FAVELA/EU SOU FAVELA
}

\author{
TRANSLATING THE IDENTITY OF BRAZILIAN FAVELA IN \\ FRANCE: JE SUIS FAVELA/EU SOU FAVELA
}

\author{
Beatriz Curti-Contessoto* \\ Maria Angélica Deângeli* \\ Lauro Maia Amorim ${ }^{* *}$
}

\begin{abstract}
RESUMO
A obra Eu sou favela (2012) é uma coletânea de contos de escritores brasileiros que narram histórias ambientadas na favela. Sua tradução, Je suis favela (2011), foi realizada pela Éditions Anacaona, uma editora francesa cujo foco é a publicação de traduções de obras brasileiras desconhecidas do grande público, tanto francês quanto brasileiro, que retratem aspectos socioculturais do Brasil. No texto em português, notamos o uso de um vocabulário de registro coloquial que foi utilizado com o intuito de melhor expressar as identidades das personagens. Assim, interessamo-nos em verificar de que modo a tradução de um dos contos, intitulado "J'suis qu'un ouf", em português "A.B.C.", valeu-se das marcas de oralidade em língua francesa, e como isso contribuiu para a criação das identidades das personagens na obra traduzida. Para tanto, fundamentamo-nos em Crépon (2004), Rodrigues (2008) e Amorim (2015), sobretudo com relação às discussões sobre o próprio conceito de tradução, à tradução como escrita que consolida literaturas não canônicas e, consequentemente, as questões identitárias subjacentes a esse processo. Também nos referimos aos trabalhos de Britto (2012) e Bagno (2012) no que diz respeito às marcas de oralidade propriamente ditas. Palavras-chave: tradução; identidade; oralidade.
\end{abstract}

\section{ABSTRACT}

Eu sou favela (2012) is a collection of short stories written by Brazilian writers who narrate stories set in slums. Its translation, Je suis favela (2011), was made available by Éditions Anacaona, a French publisher that offers translations of Brazilian fiction less known to the French and Brazilian public and which portrays sociocultural aspects of Brazil. In the source-text there is a more colloquial register that was meant to successfully render the identities of the characters. We verified the ways in which the translation of one of the short stories, entitled "J'suis qu'un ouf" ("A.B.C." in Portuguese), has resorted to orality markers in French, and how it has contributed to the creation of characters' identities in the targettext. In order to do so, we have drawn on Crépon (2004), Rodrigues (2008) and Amorim

\footnotetext{
* Doutoranda bolsista FAPESP da Universidade Estadual Paulista (UNESP), São José do Rio Preto, SP, Brasil. bfcurti@gmail.com.

** Universidade Estadual Paulista (UNESP), São José do Rio Preto, SP, Brasil. angelica.deangeli@ unesp.br

*** Universidade Estadual Paulista (UNESP), São José do Rio Preto, SP, Brasil. lauro.maia@unesp.br 
(2015), especially regarding the debates on the concept of translation itself, translation as a form of writing that consolidates noncanonical literatures and, consequently, identity issues underlying the process. We also refer to Britto (2012) and Bagno (2012) regarding to the written representation of orality.

Keywords: translation; identity; orality.

\section{INTRODUÇÃO}

A obra Eu sou favela (2012) é uma coletânea de contos de escritores brasileiros não canônicos. Seus textos narram histórias ambientadas na favela brasileira e trazem personagens inspiradas na população local. O objetivo é expor as particularidades desse ambiente tão característico do Brasil.

Por sua vez, a tradução dessa coletânea, Je suis favela (2011), foi realizada pela Éditions Anacaona - uma editora francesa que tem como foco a publicação de traduções de obras brasileiras desconhecidas do grande público que retratem aspectos socioculturais do Brasil. A ideia é partilhar com leitores franceses a cultura de nosso país a fim de torná-la conhecida na França.

Chamou-nos a atenção o fato de que, em alguns contos dessa obra, os autores valeram-se de um registro coloquial, que é observado nas marcas de oralidade e no léxico utilizados com o intuito de melhor expressar as identidades das personagens. Ao notarmos essa recorrência, interessou-nos verificar a) de que modo a tradução desses contos em Je suis favela valeu-se dessas marcas em língua francesa, e b) como isso contribuiu para a criação das identidades das personagens na obra traduzida.

Além disso, não podemos ignorar o fato de que a tradução é anterior à publicação dos textos escritos em português, deslocando assim, como assinala Marc Crépon (2004, p. 74), o "preconceito durável" de acordo com o qual a tradução viria somente em um "segundo tempo". Nesse caso, talvez fosse legítimo nos perguntar o que se apresenta como tradução e o que se dá a ler como original, vez que nas leituras conjugadas desses textos podemos depreender que ambos se caracterizam por um movimento incessante de tradução cuja particularidade reside na ideia de uma constituição "originalmente" heterogênea. É nesse contexto, e partindo de todas essas singularidades, que nos propomos a realizar uma análise da "tradução" de um desses contos. Para tanto, baseamo-nos nas pesquisas de Crépon (2004), Cristina Carneiro Rodrigues (2008) e Lauro Amorim (2015), dentre outros, mais especificamente no que diz respeito à problemática do próprio conceito de tradução, à tradução como escrita que consolida literaturas não canônicas e, consequentemente, as questões identitárias subjacentes a esse processo. 


\section{0 CONTEXTO: ESCRITAS E(M) TRADUÇÃO}

O contexto em que é feita uma tradução é revelador das complexas relações que envolvem a trama em que se procuram delinear as fronteiras entre o que é estrangeiro e o que é nacional, o que é próprio e o que é do outro. Assim, como assinala Rodrigues (2008), o contexto de uma cultura hegemônica, que produz uma tradução domesticadora, por exemplo, pode sinalizar a tentativa de apagamento do Outro por meio de procedimentos que, segundo a autora, "são caracterizados como etnocêntricos, relacionados à invisibilidade do tradutor e não éticos por significarem a apropriação do estrangeiro, no sentido de torná-lo doméstico, próprio" (p. 23).

Contudo, se mudarmos o contexto para o de uma cultura não hegemônica que adota os mesmos procedimentos no processo de uma tradução, mudamos os efeitos da relação entre estrangeiro/nacional. Nesse sentido, ainda de acordo com a autora, "uma tradução considerada não ética, porque reduz o Outro e tira-lhe a voz, passa a ser analisada como uma maneira de valorizar a cultura e a tradição nacional contrariando o hábito de prestigiar o que é estrangeiro" (RODRIGUES, 2008, p. 24).

Dessa forma, o contexto assume um papel primordial na determinação de questões culturais, ideológicas e até mesmo éticas, que marcam as escolhas do tradutor. Este, por sua vez, é (in)diretamente responsável pela construção da identidade do Outro estrangeiro no texto traduzido. Amorim (2015) ressalta que o tradutor, imerso em sua própria cultura e língua, traduz o Outro, e essa tradução é recheada de valores, significados e marcas culturais, sociais e ideológicas; para o autor $(2015$, p. 158):

Embora se afirme que o tradutor faça uma leitura da identidade do Outro estrangeiro em sua própria língua e cultura, deve-se salientar que a identidade é, em si mesma, uma forma de tradução (em um sentido mais amplo) de significados e valores tanto sociais e comunitários quanto psicológicos, na medida em que traduz a complexidade de sentimentos e autoimagens dos indivíduos em uma sociedade.

Sob essa perspectiva, o tradutor traduz a identidade do Outro estrangeiro, sendo ele próprio um inquietante estrangeiro para si mesmo (Cf. Kristeva, 1994). A identidade que esse sujeito traduz é fruto de sua imaginação que "se fundamenta em uma narrativa histórica, com seus mitos de origem e valores compartilhados socialmente" (AMORIM, 2015, p. 159).

Assim, quando se fala em país do futebol, país do carnaval e favela, de acordo com o autor, produz-se uma forma de identificação que traduz uma referência políticosocial, comunitária e, sobretudo, cultural, e que, apesar de ter um referente no 
mundo real, observa Amorim (2015, p. 159), "não deixa de ser concebida sem a complexidade do processo de 'imaginação', que inclui a construção de imagens, estereótipos, narrativas e discursos com base nos quais essas identidades são formuladas, aceitas e até mesmo contestadas ao longo da história".

Se a imaginação é constitutiva da identidade, esta, por sua vez, já é resultado de uma tradução em sua própria cultura de origem. Nesse sentido, "tratar-se-ia então de pensar a identidade cultural sob o modelo de uma identidade linguística que só se constituiria por e na tradução ${ }^{1 "}$ (CRÉPON, 2004, p. 75, tradução nossa).

Desse modo, pensar o contexto específico em que ocorre a tradução da obra Je suis favela implica direcionarmos nosso olhar para a recepção da literatura brasileira na França e nos interrogarmos sobre como a França literária lida com a literatura brasileira traduzida em francês.

Partindo do pressuposto segundo o qual todo processo tradutório envolve relações de poder, fatores externos aos textos influenciam na decisão de reconhecimento internacional de cada língua e, consequentemente, interferem em quais obras serão traduzidas e de que forma elas o serão.

Casanova (2002) descreve Paris como o "banco central" de "crédito" literário uma vez que se legitimou como "local de consagração" de muitos escritores. Para a autora (2002, p. 162), "a crença no efeito da capital das artes é tão poderosa que [...] ela tornou-se o lugar a partir do qual, julgados, criticados, transmudados, os livros e os escritores podem se desnacionalizar e assim tornar-se universais". A tradução exerce então um papel essencial no ideal de "universalização" do literário.

É interessante notar que, no mundo contemporâneo, alguns países tidos como periféricos conseguem exportar sua literatura não canônica. Desse modo, o Brasil, conforme afirma Guerini et al. (2008, p. 10), "país essencialmente importador de literatura, tem em Paulo Coelho um dos autores mais vendidos em todo o mundo", enquanto países tidos como "centrais" apresentam, de forma surpreendente, um mercado voltado à tradução de literatura estrangeira, e não somente tradução do inglês.

Além das obras de Paulo Coelho, esse movimento que relaciona as representações, as literaturas não canônicas e a competição se observa também "em traduções de autores brasileiros que, buscando se dedicar a temas pertinentes ao cotidiano das minorias, produzem obras que vão ganhando espaço além das fronteiras geográficas" (COUTINHO, 2015, p. 77).

1. Il s'agirait alors de penser l'identité culturelle sur le modèle d'une identité linguistique qui ne se constituerait que par et dans la traduction. 
Assim, a tradução torna-se, para esses escritores considerados excêntricos, um meio de aceder ao universo literário. De acordo com Casanova (2002), a tradução não é uma simples mudança de língua; ela possibilita o reconhecimento literário de obras não canônicas quando estas se dão a conhecer nos países de cultura central.

A autora considera então dois tipos de tradução. O primeiro deles é chamado intradução e consiste no fato de o dominado traduzir literatura dominante. Por sua vez, o segundo tipo é a extradução, que, segundo Casanova (2002, p. 171), passa por dois processos diferentes:

para as grandes línguas "fonte" [...], a tradução literária então concebida como "extradução" permite a difusão internacional do capital literário central. [...] Ao contrário, para as grandes línguas "alvo", isto é, quando a tradução é a importação para o centro de textos literários escritos em línguas "pequenas" ou em literaturas pouco valorizadas, a translação linguística e literária é uma maneira de anexar, de desviar obras em proveito dos recursos centrais.

É justamente esse segundo processo de extradução que caracteriza a traduçãoconsagração. Nesse sentido, a tradução para "uma grande língua literária" faz com que o texto entre para o universo literário (CASANOVA, 2002, p. 171-172).

Mais especificamente na França, a editora independente Éditions Anacaona foi criada em 2009 com o intuito de difundir a literatura brasileira não canônica produzida por autores desconhecidos do grande público. A proprietária, Paula Anacaona, é responsável por

fazer as escolhas do material a ser traduzido como, também, de todas as traduções já publicadas sob o selo da Anacaona. Com tiragens relativamente pequenas, a produção da Éditions assume o que podemos chamar de produção artesanal e doméstica, pois além de serem feitas através de escolhas pessoais, as traduções se dão, eventualmente, com o intermédio de parentes que auxiliam na compreensão da literatura estrangeira, suas nuances linguísticas e suas idiossincrasias imagéticas: espécie de diálogo colaborativo associado ao processo de traduzir. (FONSACA $_{i}$ COUTINHO, 2014, p. 157)

A editora segue, então, uma política de seleção de textos que influencia inevitavelmente no processo tradutório. Há uma preocupação por parte da Anacaona em passar para o leitor francês a sua compreensão das questões socioculturais do Brasil que subjazem aos textos. A identidade do Outro estrangeiro (no caso, do Brasil) é então traduzida na cultura de recepção/nacional (França) segundo o modo como a tradutora identifica e imagina o Brasil narrado nos textos.

Com base em Casanova (2002), consideramos que as traduções de Anacaona não são "uma simples 'naturalização' (no sentido de uma mudança de nacionalidade), ou a passagem de uma língua para outra; é, muito mais especificamente, uma "literalização" (p. 171-172). Assim, não se trata apenas de passar para a língua francesa os textos selecionados pela editora; suas traduções vão muito além: dão, a 
essa literatura não canônica, uma oportunidade de acesso ao universo literário por meio da tradução.

\section{O(S) TEXTO(S) JE SUIS FAVELA/EU SOU FAVELA}

Chama-nos a atenção o interesse da editora Anacaona em difundir em solo francês obras que, além de não serem muito conhecidas tanto no Brasil quanto no exterior, abordam questões sociais de nosso país. Para Paula Anacaona, a literatura tem "o papel político e social [...], que pode romper barreiras nacionais através da tradução" (VALENTE; CARNEIRO, 2017, p. 713).

Nesse sentido, a editora/tradutora da obra em questão entende que as sociedades brasileira e francesa tocam em alguns pontos em comum:

Há contatos entre as periferias da França e do Brasil. O sentimento de exclusão é igual em todo o mundo, por mais que as reações às vezes sejam diferentes. A luta que a literatura marginal brasileira faz para que jovens não entrem no tráfico de drogas, aqui pode ser para que eles não entrem em guerras santas, o que está acontecendo muito. (ANACAONA apud VALENTE; CARNEIRO, 2017, p. 713)

Seguindo esse viés, a obra Eu sou favela reúne contos escritos por autores brasileiros e tem como temática central a favela brasileira. Àluz da contemporaneidade, os contos abordam particularidades da favela, tais como a violência doméstica, os abusos sexuais contra menores, a hostilidade do cotidiano num meio social tão fortemente marcado pela miséria e pelas atrocidades dos crimes cometidos contra a população de modo geral, entre outros.

É interessante notar que a tradução da obra Je suis favela foi publicada em 2011 pela editora francesa antes da publicação do texto em português, que ocorreu em 2012. De fato, é notório "no trabalho da Anacaona que alguns textos brasileiros iniciaram seu contato com o grande público via língua francesa, uma vez que obras como Je suis favela foram compostas para os leitores francófonos" (COUTINHO, 2015, p. 78).

Mais especificamente neste trabalho, selecionamos um conto da coletânea intitulado "A.B.C.", a fim de realizarmos nossas análises. Trata-se de um monólogo, escrito por Rodrigo Ciríaco, de um adolescente que diz preferir a agitação das ruas e do tráfico, onde ele é mestre, a assistir a monótona aula de seu professor na escola.

2. Cabe ressaltar que outros dois volumes sobre a mesma temática foram traduzidos por Anacaona e publicados posteriormente: Je suis toujours favela (2014) e Je suis encore favela (2018). Aqui, estudamos um conto do primeiro volume da série, Eu sou favela (2012) e sua tradução Je suis favela (2011), feita pela mesma editora. 
Nesse conto, notamos uma tentativa expressiva por parte do autor em representar marcas da oralidade na língua escrita. Por marcas de oralidade, entendemos "certas marcas textuais que criem esse efeito de verossimilhança, essa impressão de que estamos lendo a fala de uma pessoa" (BRITTO, 2012, p. 87). Assim, trata-se de um caso em que houve "um interesse evidente em apresentar suas personagens como seres vivos, com relações diretas com o ambiente em que atuam, muito embora reconheçamos que tal processo nem por isso deixe de continuar sendo ficção, mera mimese seletiva da realidade" (PRETI, 2000, p. 71). Ou seja, não se trata de representar a fala exatamente como ela é, mas sim de recriá-la dentro dos limites do processo de escrita de modo que haja uma diferença visível (e não sonora) entre a forma padrão da escrita e a variante utilizada.

Britto (2012) distingue três tipos de marcas: as fonéticas (pra, né, tá, tava), as morfossintáticas (xingar ele, que nem) e as lexicais (fodido, comedor, conto (moeda)) ${ }^{3}$. De acordo com o autor, as marcas lexicais utilizadas pelo tradutor devem ser coloquialismos, ou seja, os que são conhecidos pela maior parte da população. Britto (2012, p. 93) diferencia coloquialismo de gíria, que, segundo ele, são "palavras e expressões que são usadas por grupos claramente definidos, e que são pouco utilizadas por pessoas que não pertencem a eles, sendo em muitos casos até mesmo desconhecidas por elas".

Nos contos em português e em francês por nós estudados, notamos um misto de coloquialismos e de gírias, tal como podemos verificar nas análises deste trabalho. O texto em francês, no entanto, apresenta um repertório lexical de registro informal maior do que o texto em português, que mescla os três tipos de marcas propostos por Britto $(2012)^{4}$.

Neste trabalho, é importante entendermos a diferença entre norma padrão e a variante utilizada no conto de nosso estudo. A forma convencional da escrita segue a norma padrão, que representa "um modelo de língua, um ideal a ser alcançado, um construto sociocultural que não corresponde de fato a nenhuma das muitas variedades sociolinguísticas existentes em território brasileiro" (BAGNO, 2012, p. 25). Já a norma culta "abriga um conjunto de variedades sociolinguísticas empiricamente coletáveis, expressão da atividade linguageira das cidadãs e dos cidadãos de vivência urbana e elevado grau de letramento" (BAGNO, 2012, p.

3. Exemplos dos tipos de marcas de oralidade retirados de Britto (2012).

4. Embora julguemos relevante apresentar a tipologia de marcas de oralidade proposta por Britto (2012), não é nosso objetivo neste trabalho classificar as diferentes marcas encontradas nos textos analisados. 
$25)^{5}$. Além dessas duas normas, há ainda a norma do português popular brasileiro, caracterizado por formas linguísticas geralmente estigmatizadas, por serem faladas por pessoas que vivem em zonas rurais ou nas periferias das grandes cidades, sendo este o caso do personagem retratado neste artigo. Assim, o escritor do conto aqui estudado buscou criar falas de uma personagem que não tem estudo, que é um morador de rua, que prefere o tráfico à escola e que está marginalizada na sociedade brasileira. As marcas de oralidade utilizadas no conto seguem, portanto, outro tipo de variante, diferente da norma culta utilizada por falantes com elevado grau de instrução. Trata-se de marcas de fala não padrão estigmatizadas que indicam que a personagem em questão não tem instrução formal (BRITTO, 2012, p. 88). Britto diferencia as marcas de fala não padrão (geralmente estigmatizadas) das marcas de oralidade, entendendo esta última como aquelas que "podem ser encontradas na fala de qualquer brasileiro, com qualquer nível de instrução, mas que dificilmente seriam empregadas na escrita" (BRITTO, 2012, p. 88).

No caso do conto que selecionamos para este trabalho, verificamos que a recriação da fala na escrita se deu, sobretudo, nos níveis ortográfico e lexical. As marcas de oralidade presentes no conto foram utilizadas com o intuito de representar o grupo social ao qual pertence a personagem principal. A identidade desse grupo, por sua vez, foi construída pelo autor com base na referência cultural e político-social que se tem dos jovens que vivem na favela brasileira e que muitas vezes se envolvem com o tráfico.

$\mathrm{Na}$ tradução desse conto, os aspectos discursivos utilizados para também recriar a oralidade na escrita marcam a identidade do Outro estrangeiro (Brasil) traduzido na cultura nacional (França) pela imaginação da tradutora do que representa esse mesmo grupo da favela brasileira. Dessa forma, entendemos que os elementos discursivos presentes no texto revelam a identidade traduzida do Outro - reimaginada pelo tradutor durante o processo de tradução interlingual.

Com base no exposto, buscamos neste trabalho comparar os elementos discursivos que foram utilizados tanto no original quanto na tradução para recriar as marcas de oralidade das personagens. Além disso, esperamos verificar de que modo os elementos escolhidos na tradução contribuíram para a construção da identidade desse grupo social na obra traduzida.

5. Um exemplo que esclarece essa diferença é o caso do verbo "visar". A norma padrão determina que o correto é empregar esse verbo como transitivo indireto, como em "Este projeto visa ao entendimento dos efeitos colaterais do remédio". No entanto, a norma culta, influenciada pelos usos concretos da língua por falantes letrados, sendo também moldada pela intuição linguística natural do falante, admite normalmente o verbo como transitivo direto, ou seja, "Este projeto visa o entendimento...". 
Assim, não se trata apenas de analisar elementos textuais de uma língua para outra. Consideramos que a tradução vai muito além disso. As marcas de oralidade especificamente fazem parte do cultural, ou seja, representam na escrita aspectos da cultura e da identidade de um grupo social. Ao se traduzir essa oralidade representada, traduz-se também a cultura.

Dessa forma, concordamos com Crépon (2004) para quem toda cultura é constitutivamente o resultado de uma tradução ou de uma sucessão de traduções. A suposta "autenticidade" de uma cultura estaria em sua vocação de se traduzir e em sua capacidade de acolher traduções, desmitificando assim o próprio desejo identitário em sua busca incessante pelo "autêntico da cultura". Nesse contexto, como afirma o autor, "seria quase impossível separar o original do traduzido" 6 (CRÉPON, 2004, p. 78, tradução nossa).

\section{FRAGMENTOS DE UMA ANÁLISE: REGISTROS EM QUESTÃO}

Neste trabalho, realizamos uma comparação entre o conto "A.B.C." e sua tradução, "J'suis qu'un ouf", atentando-nos especialmente às marcas de oralidade utilizadas por autor e tradutora. Nossa análise inicia-se pelos títulos do conto, visto que há uma diferença significativa entre ambos.

Em português, "A.B.C." faz referência à aprendizagem da personagem principal que, apesar de estar no ambiente escolar, é mestre no " $\mathrm{ABC}$ " do crime. Esse título não traz nenhuma marca de oralidade morfológica ou lexical. Por sua vez, "J'suis qu'un ouf" traz a omissão do e feita pelo apóstrofo em J', que é uma forma de representar a pronúncia de je em francês. Além disso, a tradutora utilizou o verlan, que é muito comum sobretudo na linguagem oral de jovens que residem na periferia de Paris, sendo, por isso, de registro informal. Trata-se de uma "codificação lexical por inversão de sílabas, inserção de sílabas postiças, sufixação, infixação sistemática, tipo particular de gíria que resulta desse processo"7 (ATILF, 2019, tradução nossa), tal como podemos observar nos seguintes exemplos: menf, como verlan de femme (mulher); vénère, como verlan de énervé (irritado). Essa forma de se expressar na fala não existe em português. Especificamente, a tradutora utilizou ouf que é o verlan de fou (louco, doido), deixando explícito o registro informal no título do conto analisado. Em francês, o título corresponderia a "eu sou doidão" - veiculando outras conotações do que aquela sugerida pela sequência $A B C$.

6. (...) il serait presque impossible de démêter l'originel du traduit.

7. (...) codage lexical par inversion de syllabes, insertion de syllabes postiches, suffixation, infixation systématique; type particulier d'argot qui en résulte. 
A seguir, expomos um trecho em português seguido de sua respectiva tradução. Trata-se do início do conto, em que a personagem conversa com seu professor (embora este não apareça no texto) e conta como se sente naquele dia de aula:

Quadro 1. Trechos retirados respectivamente do conto A.B.C. (CIRÍACO, 2013a, p. 2, grifos nossos) e de sua tradução feita por Anacaona (CIRÍACO, 2013b, p. 2, grifos nossos).

Trecho do conto original em português

Ah prussôr, eu não vou entrar não. Ele é quem manda. Tá bom, tá bom, já que o senhor insiste. Mas ó, não vou fazer lição. Ah, muleque-doido! Tô cansado. Quatro da manhã ainda era noite, Jão. Só fazendo avião. Depois, o Play 2. Não é mole não. $\mathrm{O}$ jogo é bravo. Exige concentração. Que fita eu tenho? Daquela de tiro. Plá! Plá! Plá! Me imagino tipo com uma sete-meia-cinco. Mas logo mais eu tô com uma automática na mão. É, cê vai ver, doidão.

Tradução desse trecho em francês

Ah, prof, j'vais pas entrer, ça non. C'est lui qui
commande. C'est bon, c'est bon, puisque vous
insistez. Mais, oh ! J'vais pas écouter l'cours.
Ah, quel bouffon j'suis ! J'suis claqué. Quatre
heures du matin, y faisait encore nuit, Jão. J'ai
fait l'avion'. Ensuite, d'la Play 2. C'est pas un
truc de tarlouze, non. Le jeu il est ouf. Il faut
d'la concentration. C'est quoi mon truc ? Le
tir. Pan! Pan! Pan! J'm'imagine genre avec un
sept-six-cinq. Tout de suite après, j'me retrouve
avec un automatique dans la main. Ouais, tu vas
voir, un truc de ouf.
${ }^{1}$ Livreur de drogue.

No Quadro 1, destacamos as marcas de oralidade que aparecem em ambos os textos. Como vemos, a tradutora também se valeu dessas marcas - o que pode indicar, em um primeiro momento, que a tradução se manteve coerente com o original. Ou seja, a linguagem utilizada na tradução parece ter se aproximado daquela do texto originalmente escrito em português.

Contudo, notamos que, em diversos momentos, o tipo de linguagem empregado na tradução distancia-se do original na medida em que apresenta diferenças graças a aspectos distintos que subjazem às línguas portuguesa e francesa particularmente.

Nesse sentido, é possível observarmos no Quadro 1 algumas dessas diferenças nos níveis ortográfico e lexical. A primeira delas está relacionada à grafia de algumas palavras utilizadas em ambos os textos. Notamos uma diferença na escolha de palavras para se mudar a grafia em prol de um mesmo objetivo: marcar o estilo da oralidade da personagem na escrita. Por exemplo: em português, encontramos Tá bom, tábom e, em francês, aparecem as expressões C'est bon, c'est bon, que, no contexto, representam a oralidade pelo seu registro informal e não por desvios gráficos.

Além disso, temos Tô cansado $\rightarrow$ J'suis claqué e eu tô com uma automática na mão $\rightarrow j$ 'me retrouve avec une automatique dans la main. Nessas frases, observamos que, em 
português, o autor trouxe as marcas de oralidade ao texto sobretudo por meio dos verbos - o que não acontece no texto em francês.

No conto traduzido, a tradutora optou por representar a fala da personagem na escrita valendo-se de outros elementos de grafia, tais como a abreviação de pronomes, preposições e artigos (J'vais pas écouter l'cours, j'me retrouve e Il faut $\boldsymbol{d}$ 'la concentration) e a omissão da partícula negativa ne (J'vais pas éconter ao invés de Je ne vais pas écouter). Esses elementos compensam a falta das marcas de oralidade na ortografia dos verbos, já que, em francês, o uso desse procedimento poderia dificultar o entendimento do texto. No entanto, a tradutora não opta por utilizar construções linguísticas mais subversivas com relação à norma da língua francesa ${ }^{8}$. Suas opções ficam, sobretudo, no nível do registro coloquial, diferentemente do texto em português, em que a marca de oralidade é expressa pelos desvios ortográficos dos verbos.

Outro recurso utilizado pela tradutora foi a nota de rodapé inserida por ela a fim de explicar a gíria fazer avião em francês (livreur de drogue, ou seja, entregador de drogas), uma vez que essa expressão em língua francesa significa fazer aviãozinho de papel. Mesmo em português, fazer avião é uma gíria muito particular do tráfico de drogas, ainda que seja apresentada pelo dicionário Aulete Digital (2018) como uma gíria brasileira que significa "pessoa que compra droga a traficantes e a leva ao usuário" (AULETE, 2018).

Notamos ainda o uso de palavras e de expressões que são informais na língua francesa, como bouffon para muleque-doido, claqué para cansado e truc de tarlouze para mole. Segundo o dicionário Le Petit Robert (2012), claqué é um sinônimo de registro coloquial para fatigué (cansado), truc quer dizer informalmente uma coisa qualquer e tarlouze é uma gíria vulgar para homossexual. Interessante ressaltar que c'est pas un truc de tarlouze faz, portanto, uma referência pejorativa ao homossexualismo como algo fraco (em português, seria não é coisa de viado) - o que é diferente das possíveis conotações de não é mole não do conto em português.

8. Loock (2012) analisa a tradução do inglês para o francês de obras que exploram o fenômeno do "dialeto visual" (eye dialect) em relação à grafia-fonética por meio da fala ou da escrita de seus personagens. A autora assinala as dificuldades encontradas por tradutores que tentam romper a barreira oral/ escrita. Segundo Loock (2012), "como ele é tradutor, 'a escolha das palavras permanece sempre mais ou menos suspeita' (Buckley, 2000: 269). O risco que ele corre é, com certeza, reforçado pelo conservadorismo que reina neste domínio quando se trata de traduzir para o francês, língua considerada mais cautelosa no que diz respeito ao afastamento da norma e que, frequentemente, considera esse afastamento como uma violação da língua, até mesmo uma degradação. Buckley nos lembra que é preciso ser um autor bem estabelecido como Balzac ou Queneau para ter o direito de se afastar das normas estabelecidas e rígidas, e que as obras traduzidas são ainda mais afetadas por aquilo que ele chama de 'a obediência a uma tradição centralizadora e restritiva' (ibid.: 275)" (LOOCK, 2012, p. 55, tradução nossa). 
Por sua vez, bouffon é uma palavra de registro coloquial que significa "pessoa sem interesse, besta, ridícula"9 (ROBERT, 2012, tradução nossa). Em português, o autor utilizou uma marca de oralidade ao trocar a vogal o (moleque) por $u$ (muleque) - o que não foi recriado no texto em francês. A tradutora representou a oralidade nessa passagem por meio do registro informal de bouffon, embora não tenha feito alterações ortográficas tal como consta em português. Além disso, cabe mencionar a especificidade do vocábulo muleque, que pode adquirir em certos contextos um sentido linguístico-cultural muito particular à realidade brasileira ${ }^{10}$.

A ausência de marcas de oralidade na ortografia das palavras é recorrente em todo o texto em francês. Isso porque, ao invés de marcar a oralidade desse modo no conto traduzido, a tradutora se valeu principalmente de palavras de registro informal (e que, portanto, são mais usadas na fala do que na escrita) como uma forma de provavelmente compensar a ausência dessas marcas gráficas no texto em francês.

No trecho a seguir, que é a continuação do anterior, notamos que essas diferenças se repetem nos mesmos níveis. Nessa passagem, a personagem conta brevemente a sua história e a de sua família ao professor, cujas falas não aparecem em nenhuma parte do conto. Vejamos o Quadro 2:

9. Personne sans intérêt, niaise, ridicule.

10. Segundo o Dicionário InFormal (2018), "provavelmente de origem carioca, a expressão 'ah muleque!' (inevitavelmente pontuada por um sinal de exclamação) é uma espécie de interjeição empregada com finalidades semelhantes às de 'eita', 'vixe' e demais variações regionais, sendo, no entanto, impossível de lhe traduzir amiúde. Inextricavelmente condicionada à vivência do cidadão carioca e inclusive fluminense, caracteriza-se por uma certa malemolência ou malícia na entonação (própria do falar carioca), não se excluindo aí a possibilidade de ligação com o jeito de falar dos afrodescendentes estabelecidos nessa região, além de outros fatores de viés sociológico aplicados a esse modelo de miscigenação e influências mútuas encontrável no Rio de Janeiro" (DICIONÁRIO INFORMAL, 2018). 
Quadro 2. Trechos retirados respectivamente do conto A.B.C. (CIRÍACO, 2013a, p. 2) e de sua tradução feita por Anacaona (CIRÍACO, 2013b, p. 2).

Trecho do conto original em português

Ah prussôr, não vou fazer lição não. Não entendo nada mesmo. Tô cansado de ficar só copiando. Num sei lê, num sei escrevê. Contá? Contá eu conto, claro. Trabalho com dinheiro vivo. Se eu não contá quem é que garante a minha mesada? É, a vida é cara. Quem paga meu tênis, minhas roupa de marca? Quem? Pai e mãe num tenho. Já foi. Tudo morto. Só balaço. Mas eu nem ligo. Já cicatrizô. Nem choro. É rapá, homem não chora. Só Jesus chorou. O cara era gente fina, mas ó, muito pacífico. Comigo não, é na bala. Minha vida é na quebrada. E no esquema. Nem olhe pra minha cara. Olhô, plá! Levô tiro.
Tradução desse trecho em francês

Ah, prof, j'vais pas écouter le cours, hein ? J'comprends vraiment que dalle. J'suis fatigué de rester là à copier. J'sais pas lire, j'sais pas écrire. Compter? Compter, bien sûr que je compte ! J'travaille avec du cash. Si moi je compte pas, qui c'est qui me garantira ma thune tous les mois ? Ouais, la vie elle est chère. Qui c'est qui va payer mes baskets, mes vêtements de marque ? Qui ? J'ai pas de père, j'ai pas de mère. J'en ai eu. Y sont tous morts. Canardés. Mais j'm'en branle. J'ai déjà cicatrisé. Même pas pleuré Ouais, mon pote, les hommes ça pleure pas. Y a que Jésus qu’a pleuré. Le mec, c’était un mec bien, mais oh! Un putain de pacifique ! Avec moi, non, une balle et point de barre. Ma vie, c'est l'quartier. Et l'trafic. Tu regardes pas mon visage. / Tu regardes, pan! Tu t'prends une balle.

Assim como no trecho do Quadro 1, o autor utilizou principalmente a grafia a fim de representar a oralidade e o registro informal em seu texto. No nível do léxico, há algumas palavras, como quebrada e esquema, que são gírias que, com base no contexto do conto, remetem-nos ao mundo das drogas e do crime. De acordo com o Dicionário inFormal (2018), quebrada refere-se a "lugares propícios para o uso de droga ilícitas sem se preocupar com os homem (polícia)" (DICIONÁRIO INFORMAL, 2018); e esquema significa "planejar algo, tramar algo" (AULETE, 2018) no registro coloquial. Em francês, quebrada e esquema foram traduzidas respectivamente por quartier e por trafic que não apresentam registro informal no dicionário Le Petit Robert (2012). Contudo, é importante destacar que o uso de quartier nesse contexto específico evoca uma realidade bem particular da França: os bairros das periferias francesas que refletem a exclusão de jovens marginalizados que não conseguem bons empregos e não têm acesso a boas escolas (ou seja, estão à margem da sociedade), sobretudo, por serem, em sua maioria, franceses filhos de estrangeiros

Com relação às mudanças ortográficas, em português, as marcas de oralidade aparecem em verbos infinitivos ( $\hat{e}$, escrevê, contá, cicatrizô, olbô), na ausência de concordância do plural (minhas roupa) e em algumas palavras (prussôr, rapá, num). Em francês, nos trechos correspondentes, a oralidade não foi marcada da mesma forma: os verbos e a concordância do plural seguiram a escrita da norma padrão francesa 
(ainda que, na fala, a letra $s$ não seja pronunciada nesses casos e os verbos tenham uma pronúncia diferente do modo como se escrevem). No entanto, se a tradutora tivesse feito as marcações nos mesmos lugares, o leitor da tradução provavelmente teria dificuldades em compreender o que estaria escrito. Por exemplo, se ela tivesse optado por j'sè pá lir ao invés de j'sais pas lire, o leitor se depararia com uma construção cuja decodificação parece não ser tão clara.

Assim, ela manteve o uso de apóstrofo (como em j' no lugar de je) e a omissão da partícula negativa ne (je compte pas e não je ne compte pas) e do pronome il ( $y$ a ao invés de il y a) em alguns casos para marcar a oralidade no texto. Em compensação, a tradutora recorreu a um léxico que, de acordo com o dicionário Le Petit Robert (2012), são de registro informal. Além disso, essas unidades léxicas indicam a construção da imagem de uma pessoa marginal. Nesse sentido, encontramos que dalle (nada), cash (dinheiro vivo), thune (mesada), canardés (só balaço), j’m'en branle (eu nem ligo), pote (rapá), putain de pacifique (muito pacífico) e une balle et point de barre (é na bala).

Dentre as opções feitas pela tradutora, destacamos o uso de se branler para traduzir a ideia de não se importar com o assunto em questão. Em francês, se branler é uma gíria vulgar que significa se masturbar (ROBERT, 2012) e é utilizada informalmente para se dizer algo como tô cagando pra isso. Assim sendo, essa é mais uma palavra em francês que traz uma conotação sexual ao texto - o que não ocorre na versão em português.

Além disso, julgamos interessante o fato de a tradutora ter escolhido a expressão putain de pacifique para traduzir muito pacífico. Em francês, ela optou por putain (puta) ao invés de um simples très (muito) tal como consta no texto em português. Se o autor quisesse trazer um vocábulo de baixo calão ao seu texto, teria escrito um puta pacífico e não muito pacífico, já que também é uma construção possível em português falado.

A situação se repete no trecho a seguir: 
Quadro 3. Trechos retirados respectivamente do conto A.B.C. (CIRÍACO, 2013a, p. 2) e de sua tradução feita por Anacaona (CIRÍACO, 2013b, p. 2).

Trecho do conto original em português

Quem guia a minha mão é o Marcola. Se eu já matei? Eh prussôr, da missa cê não sabe o terço? Já tenho treze anos pô. Sô bicho solto, bicho feito. Tô enquadrado. É, já tô viradasso. Já paguei até veneno. Um ano na FEBEM. Várias rebelião e o caralho. Tô aqui de L.A., só por causa do juiz. Mêmo assim, num tem quem me segura. Fico pelos corredor, só nas fissura. Dando umas volta, ganhando a fita. Estudá? Só entro na aula do senhor porque o prussôr é gente fina. Mas não estudo não. E só entro de vez em quando. É, não tem mais jeito, Jão. É feio ficar chorando pelo que se rebentô, já se estragô. Tem defeito. Minha vida agora é assim, só no arrebento. Mudá? Só se for de ponto. De vida eu não quero não. Tô bem, prussôr. Valeu a preocupação, satisfação
Tradução desse trecho em francês

Qui c'est qui guide ma main, c'est Marcola. $\mathrm{Si}$ j'ai déjà refroidi quelqu'un ? $\mathrm{Oh}$, prof, tu vas à la messe et tu connais pas ton rosaire ? Porra, j'ai treize ans. J'suis un loup solitaire, un loup adulte. J'suis dans la place. Yep, j'suis qu'ouf, tout droit sorti d'zonzon. Un an de prison pour mineurs ${ }^{2}$. Plusieurs rébellions et le bordel. J'suis en liberté conditionnelle, grâce au juge ! Même comme ça, y a personne qui m'gère. Je reste dans les couloirs, dans les brèches, juste là, quoi. Je zone, j'vois les biz qui s'font. Etudier? J'me pointe dans votre classe juste parce que vous êtes un mec bien, prof. Mais j'étudie pas, ça non. Et j'me pointe que de temps en temps. Ouais, y a pas moyen, Jão. Ça sert à quoi d'rester à chialer, une fois que c'est pété c'est foutu. Y a des défauts. Ma vie est comme ça, ça pète tout le temps. Changer ? Juste de point de vente. De vie, j'veux pas, ça non. J'suis bien, prof. Merci d'vous en faire.

${ }^{2} \mathrm{Au}$ Brésil, la FEBEM.

O que mais nos chamou a atenção nesse trecho são os acréscimos feitos pela tradutora. Nesse sentido, porra foi utilizado para traduzir pô. A palavra porra tem origem obscena e "exprime admiração, espanto, raiva, surpresa, chateação, impaciência etc" (AULETE, 2018) e tem como variações pô, poça e poxa. A opção de trazer uma palavra em português para o texto em francês é algo a ser observado já que seria possível traduzir pô por merde, por exemplo. De modo contrário, a tradutora optou por traduzir caralho por bordel, que é uma palavra de baixo calão em francês e que significa muita desordem (ROBERT, 2012).

No restante do conto, a tradutora aproximou o texto para as particularidades da língua francesa por meio de sua tradução ao utilizar notas, bem como palavras e expressões comuns na linguagem oral em francês, mas que não correspondem às do conto em português. Além disso, os nomes próprios não foram alterados. Desse modo, Marcola, que é conhecido no contexto brasileiro como um grande chefe do tráfico, torna-se apenas um nome como qualquer outro em francês. 
Nesse sentido, outro acréscimo é o de quoi em Je reste dans les couloirs, dans les brèches, juste là, quoi. Esse vocábulo é recorrente na linguagem oral em francês. Ele tem a função de pontuar o que foi dito, como se fosse o né do português.

Além desses acréscimos, a tradutora inseriu uma nota de rodapé para explicar que, no Brasil, a FEBEM (Fundação Estadual para o Bem Estar do Menor) é uma prisão para menores infratores (prison pour les mineurs). Contudo, notamos que, ao invés de manter o original FEBEM e inserir a nota explicativa, a tradutora optou por colocá-lo em nota e substituí-lo pela explicação desse termo no corpo do texto. Fazendo assim, ela dá ao leitor a ideia de que se trata de uma prisão para menores (como qualquer outra que possa existir no Brasil ou na França). Atualmente, essa instituição foi substituída pela Fundação da Infância e da Adolescência (FIA) no Rio de Janeiro, mas a palavra FEBEM continua sendo utilizada para se referir à prisão de menores como uma fábrica de produção de jovens criminosos.

Em outro momento, a tradutora opta por fazer outro acréscimo explicativo, point de vente, enquanto que, em português, o autor utilizou apenas ponto. Isso se deu porque, de fato, em francês a palavra point não recupera sozinha o sentido de local de venda de drogas.

Outra questão interessante diz respeito às marcas de oralidade que ocorrem na versão em português, mas que não aparecem em francês. No Quadro 3, encontramos as ocorrências verbais que denotam processos fonológicos, como em apócope, Sô (Sou), Estudá (Estudar), estragô (estragou) e Mudá (Mudar), e em aférese, Tô (Estou) e rebentô (arrebentou). Nesses casos, o autor valeu-se da ortografia desses verbos para representar na escrita o modo como a personagem fala essas palavras. Já em francês, os verbos seguiram a norma padrão: suis $\rightarrow$ Sô e Tô, Etudier $\rightarrow$ Estudá, pété $\rightarrow$ rebentô, foutu $\rightarrow$ estragô, Changer $\rightarrow$ Mudá, embora nada impedisse a tradutora de explorar os limites de uma correspondência grafia-fonética ${ }^{11}$.

Observamos ainda que, em alguns momentos, não há concordância de plural na obra em português: Várias rebelião, pelos corredor, nas fissura, umas volta. Esse recurso foi usado pelo autor na tentativa de representar a oralidade. Na tradução em francês, essa marca desaparece.

Em outro trecho, encontramos satisfação que é uma forma bem informal e particular de se dizer estar agradecido(a) ${ }^{12}$. Ficou apenas merci, que é a forma mais neutra para expressar agradecimento em francês.

11. Para um estudo detalhado do assunto, Cf. os exemplos explorados por Look (2012).

12. Apesar de saber que satisfação tem, de fato, esse uso de registro informal com base em nossa análise do conto em português, não encontramos a acepção de estar agradecido(a) em nenhum dos dicionários consultados (AULETE, 2018; DICIONÁRIO INFORMAL, 2018). 
A tradutora, então, compensa de outras formas, dentre as quais está a variação ortográfica de alguns vocábulos (j' e d') e a omissão de alguns elementos, como em [il] y a des défauts e j' [ne] veux pas, além do uso de palavras de registro informal. Assim, encontramos o verbo refroidir que, em sentido coloquial, significa assassinar alguém (ROBERT, 2012) ; zonzon é uma gíria para prisão (DICTIONNAIRE DE LA ZONE, 2018); chialer que significa chorar e é usado em registro informal (ROBERT, 2012); c'est pété que uma forma informal de se dizer quebrar em francês (ROBERT, 2012); c'est foutu que significa tá fodido (ROBERT, 2012), mas foi utilizado para traduzir estragô.

A seguir, expomos o último excerto do conto que é continuação do anterior:

Quadro 4. Trechos retirados respectivamente do conto A.B.C. (CIRÍACO, 2013a, p. 2) e de sua tradução feita por Anacaona (CIRÍACO, 2013b, p. 2).

Trecho do conto original em português

Ah, muleque-doido! Ó, tô saindo. Cansei de ficar na sala de aula, na escola, sei lá. Aqui é tudo muito parado. Vou pra rua. Lá que é o barato. É. Lá eu já sou mestre.
Tradução desse trecho em francês

Ah, j'suis qu'un bouffon! Oh, j'me casse ! J'suis fatigué de rester en classe, à l'école, j'sais pas quoi. Ici, ça bouge pas. J'vais dans la rue. C'est là qu'ça s'passe. Ouais. Là, j'maîtrise.

Nesse último trecho, a tradutora se manteve coerente com as escolhas feitas ao longo do conto. Há, porém, o uso do verbo se casser para traduzir tô saindo. Em francês, esse verbo é de registro coloquial e significa ir embora apressadamente (ROBERT, 2012). Apesar de o verbo sair em português não ter esse tipo de registro, o gerúndio utilizado pelo autor representou a oralidade da personagem - o que foi recuperado pelo registro informal da palavra se casser em francês.

Com base nessas observações, verificamos que a tradutora se valeu principalmente de um repertório lexical de registro informal. Já o autor do conto em português preferiu representar a oralidade, sobretudo, por meio de recursos ortográficos. Nesse sentido, percebemos que algumas palavras e expressões utilizadas pela tradutora são mais marcadas do que as que constam no conto em português, tais como un truc de tarlouze, j'm'en branle, un putain de pacifique e c'est foutu que, como exposto anteriormente, dão à escrita uma conotação pejorativa e sexualizada, o que não ocorre necessariamente em português.

O repertório lexical que a tradutora utilizou ao longo do conto é muito comum na linguagem de jovens moradores da banlieue ${ }^{13}$. Na França, essas periferias são conhecidas como "zonas de conflito" em que afloram inúmeros problemas sociais decorrentes da coexistência nem sempre amigável entre as várias populações que ocupam esses espaços. Os jovens moradores dessas banlieues, com um nível de

13. Periferia francesa. 
escolaridade frequentemente precário, difícil acesso ao mercado de trabalho e a melhores condições de vida, fazem do quartier o local da reivindicação identitária por excelência. Conforme afirmam Messili e Aziza o quartier é seu território e "representa o único espaço de sua posse e de seu domínio"14 (2004, p. 1, tradução nossa).

Nesse sentido, a linguagem é o principal meio utilizado por esses jovens para exprimir a insatisfação para com a sociedade e se rebelarem contra uma política que consideram por demais hostil e discriminadora. Tal linguagem é conhecida como o français des cités que "é uma espécie de gíria (no sentido linguístico) contemporânea dentre outras, essencialmente identitária" ${ }^{15}$ (MESSILI; AZIZA, 2004, p. 2, tradução nossa).

O français des cités apresenta empréstimos (como cash, por exemplo) e o truncamento e a inversão das palavras (como o verlan). Especificamente, o verlan representa o reflexo de um espelho "que manifesta a diferença de locutores que recusam se reconhecer na língua normativa"16 (MESSILI; AZIZA, 2004, p. 2, tradução nossa). $\mathrm{O}$ uso dessa linguagem acentua a oposição e o distanciamento que esses jovens sofrem com relação àqueles que não pertencem às banlieues. Assim, eles "elaboram por meio da linguagem estratégias de afirmação de uma identidade conflitante e essa relação com a língua não valoriza nem a comunicação, nem a troca, nem a compreensão do mundo ou de si"17 (MESSILI; AZIZA, 2004, p. 4, tradução nossa).

Para as autoras, os jovens das banlienes utilizam esse tipo de linguagem com o intuito de se fecharem dentro de seu grupo e da periferia onde moram, sendo que esse fechamento é frequentemente voluntário e "uma autoexclusão diante da exclusão da qual eles são alvo"18 (MESSILI; AZIZA, 2004, p. 4, tradução nossa).

Além da exclusão, as periferias são vistas com preconceito em virtude de sua má reputação fora desses locais. Consequentemente,

os jovens assumem totalmente a imagem da cité que representa para eles uma "pátria". A gestão dessa imagem encontra sua especificidade por sua vez em uma exacerbação dos sentimentos e na violência simbólica de certas práticas comunicativas e de linguagem inadequadas, que transgridem as regras geralmente admitidas: uso de um vocabulário de forte conotação sexual

14. (...) représente le seul espace possédé et maîtrisé.

15. (...) est un type d'argot (dans le sens linguistique) contemporain parmi d'autres, essentiellement identitaire.

16. (...) qui manifeste la différence de locuteurs refusant de se reconnaître dans la langue normée. C'est pourduoi, il est largement utilisé dans les cités.

17. Les jeunes des banlieues élaborent par le biais du langage des stratégies d'affirmation d'une identité conflictuelle et ce rapport au langage ne valorise ni la communication, ni l'échange, ni la comprébension du monde ou de soi.

18. (...) une auto-exclusion devant l'exclusion dont ils font l'objet. 
ou escatológica, reflexões impertinentes ou injuriosas ${ }^{19}$. (MESSILI; AZIZA, 2004, p. 2, tradução nossa)

É nesse sentido que entendemos a ocorrência de algumas palavras com forte conotação sexual no conto em francês, tais como un truc de tarlouze e j'm'en branle, por exemplo. Além disso, numerosas expressões fazendo apelo à violência estão presentes na linguagem das banlieues - o que explica o vocabulário de tom agressivo utilizado pela tradutora no conto.

\section{CONSIDERAÇÕES FINAIS}

Partindo das observações de Messili e Aziza (2004), podemos considerar que a tradutora do conto aqui estudado se inspirou na linguagem dos jovens das banlienes a fim de representar a oralidade em sua tradução por meio do uso de um vocabulário de registro informal, visando retratar a linguagem utilizada por jovens das periferias francesas. Em nossas análises, observamos que a tradutora preferiu não ferir a ortografia dos vocábulos utilizados no texto. Ela não interfere na tradição beletrista francesa que presa pelas belas formas e pelo padrão (Cf. nota 8). Assim, a identidade da personagem é reconstruída adquirindo novos tons em francês, já que a ortografia e a representação fonética da língua são preservadas. Consideramos que essa seja uma forma de domesticação para dar voz ao outro.

Assim, entendemos que Anacaona faz uma relação entre os jovens da favela brasileira e os jovens das periferias francesas, aproximando-os em virtude sobretudo da exclusão que eles sofrem em ambas as sociedades. Ao fazê-lo, no entanto, a tradutora apaga de certa forma a identidade da personagem do conto em português (adolescente, traficante de drogas, morador de uma favela do Brasil) ao transpô-la para outro espaço (uma periferia francesa onde moram jovens franceses descendentes de estrangeiros, mulçumanos em sua maioria e provenientes de excolônias da França).

Apesar de esses jovens sofrerem preconceito e exclusão social, há de se levar em consideração que isso acontece por motivos diferentes no Brasil e na França. Aqui, os problemas enfrentados por esses jovens marginalizados estão associados, principalmente, ao crime e ao tráfico que existem nas favelas brasileiras. Na França, os jovens sofrem sobretudo por não serem vistos, tal como reafirmam os discursos

19. (...) Les jeunes assument pleinement l'image de la cité qui représente pour eux une "patrie ». La gestion de cette image trouve sa spécificité à la fois dans une exacerbation des sentiments et dans la violence symbolique de certaines pratiques langagières et communicatives inadéquates, transgressant les règles généralement admises: usage d'un vocabulaire à forte connotation sexuelle ou scatologique, réflexions impertinentes ou injurieuses. 
e as políticas de exclusão que tomam conta do cenário internacional, como franceses legítimos, ou seja, francês de origem (français de souche)

É a questão da legitimidade que merece ser então questionada e com ela o mito da origem. Se partimos do princípio que a tradução se tece no devir de um "sempre" cujo efeito, como assinala Crépon (2004, p. 73, tradução nossa), "é tornar caduco todo recurso a uma hipotética origem ${ }^{\prime 20}$, o que pode legitimar um discurso que reivindica a soberania dos français de souche em detrimento daqueles cuja origem se encontra desde sempre em movimento, desviada de sua origem mítica?

Conforme sublinha Deângeli (2012, p. 43-44), a palavra souche "pode ser definida como aquilo que sobra do tronco, com as raízes, quando uma árvore foi cortada" [...]. Em seu sentido 'figurado', souche designa a 'pessoa que está na origem de uma família, de uma série de descendentes, de uma linhagem". De acordo com a autora, a metáfora da árvore, "implícita na designação de français de souche para falar de francofonia, contribui para reiterar a ideia de um centro a partir do qual falariam (e escreveriam) legitimamente, já que legitimados pela própria posição que ocupam na árvore, a saber, o que lhes dá sustentação, os escritores franceses" (DEÂNGELI, 2012, p. 44). A autora trabalha essa questão para discutir o(s) lugar(es) dos escritores que, não sendo de "origem" francesa, escrevem em francês e ao fazê-lo realizam em seu próprio ato de escrita, na "origem" de seu dizer, um trabalho incessante de tradução.

É nos deslocamentos dessa origem, dessa souche para sempre inalcançável que devemos então apreender os movimentos tradutórios dessas duas escritas que se dão a ler como uma experiência singular da favela brasileira no Brasil e na França. E é dessa experiência singular da leitura e da língua, como experiência da tradução, que nos fala incessantemente Crépon (2004). Para o autor:

Traduzir, mas também se confrontar com traduções (ler traduções), é ter uma experiência de sua língua que torna impossível se fechar em uma cultura determinada, é desvincular a experiência e a prática da língua [...] de todo sentimento de pertencimento. ${ }^{21}$ (CRÉPON, 2004, p. 72, tradução nossa).

Assim, ao sermos confrontados com a leitura e a tradução de Je suis favela e Eu sou favela - o que já se apresenta como uma difícil tarefa classificatória, se quisermos atribuir um "primeiro tempo" a uma dessas escritas -, somos inevitavelmente convidados a colocar à prova o discurso da apropriação linguística. Nas leituras/

20. (...) est de rendre caduc tout recours à une bypotbétique origine.

21. Traduire, mais aussi être confronté à des traductions (lire des traductions), c'est avoir une expérience de sa langue qui rend impossible son repli sur une culture déterminée, c'est désolidariser l'expérience et la pratique de la langue [...] de tout sentiment d'appartenance. 
escritas paralelas desses dois contos o que irrompe com toda força é a tradução como exercício pleno da inventividade, da desapropriação e da desterritorialização. $\mathrm{Na}$ linguagem da favela brasileira ou da periferia francesa só há um imperativo do qual não podemos nos esquivar: "isso se traduz" (ça se traduit) ou simplesmente "isso traduz" (ça traduit) (CRÉPON, 2004, p. 74). O sentido ou a direção em que leremos esse traduzir dependerá das contingências de cada sujeito. Mas o que conta nesse movimento é que em toda língua e em toda cultura sempre há tradução.

\section{$\overline{\text { REFERÊNCIAS }}$}

AMORIM, L. M. (2015). Tradução \& Identidade. In: AMORIM, L. M. et al. (Orgs.) Tradução \&: Perspectivas teóricas e práticas. São Paulo: Editora UNESP. p.155-182.

ANACAONA, P. (2013a). Eu sou favela [e-book]. França: Éditions Anacaona.

ANACAONA, P. (2013b). Je suis favela [e-book]. Tradução de Paula Anacaona. França: Éditions Anacaona.

ATILF. (2019). Trésor de la Langue Française informatisé. Disponível em: < htttp://atilf.atilf.fr/> Acesso em 07 de mar. 2019.

AULETE. (2018). Aulete Digital. Disponível em: $<\underline{\text { http: } / / w w w . a u l e t e . c o m . b r />~}>$. Acesso em 17 jul. 2018.

BAGNO, M. (2012). Norma linguística, hibridismo e tradução. Traduzires. Brasília, v. 1, nº 1, pp. 19-32. Disponível em: < http://periodicos.unb.br/index.php/traduzires/article/ view/6652/5368 >. Acesso em 25 abr. 2018.

BRITTO, P. H. (2012). A tradução literária. Rio de Janeiro: Civilização Brasileira.

CASANOVA, P. (2002). A República Mundial das Letras. Tradução de Marina Appenzeller. São Paulo: Estação da Liberdade.

CIRÍACO, R. (2013a). A.B.C. In: ANACAONA, P. Eu sou favela [e-book]. França: Éditions Anacaona, pp. 1-2.

CIRÍACO, R. (2013b). J'suis q'un ouf. Tradução de Paula Anacaona. In: ANACAONA, P. Je suis favela [e-book]. França: Éditions Anacaona, pp. 1-2.

CRÉPON, M. (2004). La traduction entre les cultures. Revue germanique internationale, $\mathrm{n}^{\mathrm{o}} 21$, pp. 71-82. Disponível em: < https://rgi.revues.org/998 > . Acesso em: 5 set. 2017. 
COUTINHO, J. A. (2015). Literaturas não canônicas e a tradução de antologias de contos brasileiros. In: SIMÃO, A. K. G.; DEÂANGLLI, M. A. (Org.). Tendências contemporâneas dos estudos da tradução (vol.1). São José do Rio Preto: UNESP - Câmpus de São José do Rio Preto.

DEÂNGELI, M. A. (2012). A literatura na língua do outro: Jacques Derrida e Abdelkebir Khatibi. São Paulo: Editora UNESP.

DICIONÁRIO INFORMAL. (2018). Dicionário InFormal. Disponível em: < https://www. dicionarioinformal.com.br/>. Acesso em 17 jul. 2018.

FONSACA, K.; COUTINHO, J. A. (2014). O ato tradutório e os gestos culturais: enfoque sobre o conto Polícia ladrão - Police voleur, de Marcelino Freire. Cultura \& Tradução. João Pessoa, v. 3, nº 1, pp. 156-167.

GUERINI, A. et al. (2008) Literatura traduzida e literatura nacional. Rio de Janeiro: 7Letras.

KEYES, D. (2011). Des Fleurs pour Algernon. Tradução de Georges Gallet. Paris: Flammarion.

KRISTEVA, J. (1994). Estrangeiros para nós mesmos. Rio de Janeiro: Rocco.

PRETI, D. (1977). Sociolinguística: os níveis de fala. São Paulo: Ed. Nacional.

LOOCK, R. (2012). Komen traduir l'inovassion ortografik : étude de ca. Revue de Traduction Palimpsestes, $\mathrm{n}^{\mathrm{O}}$ 25, pp. 39-65. Disponível em: < https://journals.openedition.org/ palimpsestes $/ 1037>$ Acesso em 16 out. 2018

MESSILI, Z.; AZIZA, H. B. (2004). Langage et exclusion. La langue des cités en France. Cabiers de la Méditerranée, v. 69, pp. 23-32. Disponível em: < https://journals. openedition.org/cdlm/729 >. Acesso em 17 jul. 2018.

ROBERT. (2012). Le Petit Robert. França: Le Robert.

RODRIGUES, C. C. (2008). A ética da apropriação. Tradução \& Comunicação-Revista Brasileira de Tradutores, $\mathrm{n}^{\mathrm{O}} 17$, pp. 21-28.

VALENTE, M. I.; CARNEIRO, T. D. (2017). Literatura afro-brasileira rompendo barreiras através da tradução: algumas considerações sobre a recepção de Ponciá Vicêncio na França. Trabalhos em Linguística Aplicada, no 56.2, mai./ago., pp. 711-728.

Recebido: 3/11/2018

Aceito: 27/03/2019

Publicado: 29/03/2019 